\title{
Invasion and Colonization Pattern of Fusarium fujikuroi in Rice
}

\author{
Chieh-Yi Chen, ${ }^{1}$ Szu-Yu Chen, ${ }^{1}$ Chun-Wei Liu, ${ }^{1}$ Dong-Hong Wu, ${ }^{2,3}$ Chien-Chih Kuo, ${ }^{4}$ Chun-Chi Lin, ${ }^{5}$ Hau-Ping Chou, ${ }^{6}$ \\ Yu-Yao Wang, 6 Yi-Chen Tsai, ${ }^{7}$ Ming-Hsin Lai, ${ }^{2}$ and Chia-Lin Chung1, ${ }^{\dagger}$ \\ ${ }^{1}$ Department of Plant Pathology and Microbiology, National Taiwan University, No. 1, Sec. 4, Roosevelt Rd., Taipei City 10617, Taiwan \\ ${ }^{2}$ Crop Science Division, Taiwan Agricultural Research Institute, Council of Agriculture, No. 189, Chung-Cheng Road, Wufeng, Taichung City \\ 41203, Taiwan \\ ${ }^{3}$ Department of Agronomy, National Chung Hsing University, No. 145, Xingda Rd., South District, Taichung City 40227, Taiwan \\ ${ }^{4}$ Crop Environment Section, Taichung District Agricultural Research and Extension Station, Council of Agriculture, No. 370, Song Hwai Road, \\ Tatsuen Hsiang, Changhua County 51544, Taiwan \\ ${ }^{5}$ Crop Environment Section, Taitung District Agricultural Research and Extension Station, Council of Agriculture, No. 675, Chunghua Rd., Sec. \\ 1, Taitung City 95055, Taiwan \\ ${ }^{6}$ Crop Environment Section, Kaohsiung District Agricultural Research and Extension Station, Council of Agriculture, No. 2-6 Dehe Rd., Dehe \\ Village, Changjhih Township, Pingtung County 90846, Taiwan \\ ${ }^{7}$ Crop Environment Section, Hualien District Agricultural Research and Extension Station, Council of Agriculture, No. 150, Sec. 2, Ji'an Rd., \\ Ji'an Township, Hualien County 97365, Taiwan \\ Accepted for publication 13 July 2020 .
}

\section{ABSTRACT}

Bakanae disease in rice can cause abnormal elongation of the stem and leaves, development of adventitious roots, a larger leaf angle, and even death. Little is known about the infection, colonization, and distribution of Fusarium fujikuroi in rice plants across different growth stages. In this study, microscopic observation and quantitative real-time PCR were combined to investigate the pathogenesis of bakanae, using artificially inoculated seedlings of a susceptible rice cultivar, Zerawchanica karatals (ZK), a resistant cultivar, Tainung 67 (TNG67), naturally infected adult field plants (cultivars Kaohsiung 139, Taikeng 2, and Tainan 11), and an $F$. fujikuroi isolate expressing green fluorescent protein. In rice seedlings, F. fujikuroi hyphae were found to directly penetrate the epidermis of basal stems and roots, then extend inter- and intracellularly to invade the vascular bundles. Occlusion of vascular bundles and radial hyphal expansion from vascular bundles to surrounding parenchyma were observed in adult plants.
Analysis of consecutive 3-cm segments of the whole plant revealed that F. fujikuroi was largely confined to the embryo, basal stem, and basal roots in seedlings, and distributed unevenly in the lower aerial parts (including nodes and internodes) of adult plants. The elongation and development of adventitious roots did not necessarily correlate with the amount of $F$. fujikuroi in diseased plants. Treatment of rice seeds with gibberellic acid-3 $\left(\mathrm{GA}_{3}\right)$ at $0.5 \mathrm{mg} /$ liter resulted in significantly more elongation of ZK than TNG67 seedlings, suggesting that the susceptibility of ZK to bakanae is associated with its higher sensitivity to $\mathrm{GA}_{3}$.

Keywords: adventitious roots, bakanae disease, fluorescence microscopy, Fusarium fujikuroi, gibberellic acid, mycology, pathogenesis, real-time quantitative PCR, vascular bundles
Bakanae disease of rice, caused by Fusarium fujikuroi Nirenberg [teleomorph Gibberella fujikuroi (Sawada) Ito] (Ito and Kimura 1931; Nirenberg 1976; O’Donnell et al. 1998), was first identified in 1828 in Japan and spread widely to all major rice cultivation areas (Ito and Kimura 1931; Jeon et al. 2013; Karov et al. 2009; Kim et al. 2015; Singh and Sunder 1997). It can lead to great yield losses ranging from 20 to $50 \%$ (Ito and Kimura 1931; Ou 1985). In recent years, increasing incidence and severity of bakanae disease has been reported in Italy, Pakistan, Malaysia, Indonesia, Bangladesh, India, and South Korea (Gupta et al. 2014; Haq et al. 2011; Khan et al. 2000; Kim et al. 2015; Matić et al. 2017; Zainudin et al. 2008). In Taiwan, a bakanae disease epidemic was first reported in the eastern region, and then became commonly observed throughout Taiwan (Chen et al. 2016). In eastern Taiwan in 2009, two main cultivars,

${ }^{\dagger}$ Corresponding author: C.-L. Chung; clchung@ntu.edu.tw

Funding: Support was provided by the Council of Agriculture (108AS-8.4.4-BQB1 and 109AS-8.4.2-BQ-B3) and the Ministry of Science and Technology, Taiwan (106-2313-B-002-021-MY3).

*The $\boldsymbol{e}$-Xtra logo stands for "electronic extra" and indicates that four supplementary figures are published online.

The author(s) declare no conflict of interest.

(C) 2020 The American Phytopathological Society
Kaohsiung 139 (KH139) and Taikeng 2 (TK2), showed a disease incidence of 10 to $15 \%$ (Huang and Chu 2009). In central Taiwan in 2012, disease incidences of $30.4 \%$ for the cultivar Taikeng 8 and $14.5 \%$ for Taikeng 9 (Zheng et al. 2016), and 12 to $14 \%$ for Tainung 71, and 6 to $8 \%$ for Taikeng 16 (Kuo et al. 2014) were reported.

Bakanae disease can cause various types of disease symptoms, ranging from blight, slenderness, stunting, a large leaf angle, crown rot, root rot, sterility and discoloration of grains (Desjardins et al. 2000; Huang and Chu 2009; Ou 1985; Sun and Snyder 1981; Webster and Gunnell 1992). The most characteristic symptoms are etiolation, hypertrophy and excessive or abnormal elongation (Gupta et al. 2014). Kurosawa (1926) first proposed that a chemical produced by the pathogen may be responsible for the elongation of diseased plants. Identified from the culture filtrate of the bakanae pathogen (Yabuta and Sumiki 1938), gibberellic acid (GA) was found to be a key factor causing anomalous elongation symptoms in the infected plants (Matić et al. 2017).

Bakanae is considered a seedborne and soilborne disease (Kanjanasoon 1965; Lin 2015; Ou 1985). F. fujikuroi can produce microconidia, macroconidia, and ascospores (Leslie and Summerell 2006; Sun 1975). Rice seeds contaminated by ascospores during flowering or by conidia during harvesting (Sun 1975) are the main inoculum in the following season (Matić et al. 2017). Macroconidia and thick-walled hyphae in plant debris and soil can also serve as the inoculum (Kanjanasoon 1965; Lin 2015; Ou 1987; Watanabe 1974). Due to the lack of chlamydospores, F. fujikuroi populations 
in the field diminish quickly after host debris is decomposed (Leslie and Summerell 2006; Sun 1975).

The infection, colonization, and distribution of $F$. fujikuroi in rice have been investigated in a few studies. By introducing the spores of F. fujikuroi to rice seeds and various parts (wounded and nonwounded) of 2- to 4-cm height seedlings, Sun (1975) suggested that F. fujikuroi can infect plants through the seeds, stem base, and root tip, but not the stem, leaf blade, or leaf axil. Sunani et al. (2019) proved that inoculation of rice seeds, seedlings, and florets can lead to systemic infection and seed transmission of $F$. fujikuroi. By performing scanning electron microscopy, Sunani et al. (2019) also observed different types of infectious structures (i.e., swollen tip hyphae, infectious hyphae, appressoria, and infection cushions) and the intra- and intercellular colonization of $F$. fujikuroi. Researchers have used fluorescent $F$. fujikuroi isolates to observe hyphal interactions with the biocontrol agent Talaromyces sp. KNB-422 (Kato et al. 2012) and the early root colonization of a GA-producing wild-type and a GA-deficient mutant strain (Wiemann et al. 2013). By conducting hand sectioning and tissue isolation using the internodes of diseased field plants approaching the heading stage, Nisikado and Kimura (1941) discovered a wide distribution of $F$. fujikuroi hyphae and microconidia within vascular vessels and neighboring parenchyma cells in rice culms. Naito et al. (2008) also observed colonization of $F$. fujikuroi in the vascular system in naturally infected rice seedlings at the transplanting stage.

As an emerging threat to rice production, bakanae disease has drawn increasing attention over the last few decades (Gupta et al. 2015; Matić et al. 2017). Research efforts have been directed toward uncovering the whole genome sequences (Jeong et al. 2013; Wiemann et al. 2013) and population genetics of $F$. fujikuroi (Chen et al. 2016; Valente et al. 2017), fungal metabolites responsible for bakanae symptoms (Niehaus et al. 2016), and rice resistance against F. fujikuroi (Chen et al. 2019; Hur et al. 2015; Matić et al. 2016; Volante et al. 2017). In addition, SYBR green and TaqMan quantitative real-time PCR (qPCR) techniques have been developed for detection and quantification of $F$. fujikuroi in rice seeds and seedlings (Amatulli et al. 2012; Carneiro et al. 2017). To provide new insights into the interplay between rice and $F$. fujikuroi, the objectives of this research were to (i) investigate the infection and colonization of $F$. fujikuroi in the seedlings of resistant and susceptible rice cultivars; (ii) examine the spatial distribution of
F. fujikuroi in diseased seedling and adult plants; and (iii) assess the relationship between bakanae symptoms and the level of $F$. fujikuroi colonization in rice. The infection and colonization processes of $F$. fujikuroi were examined in more detail and at a better resolution using a newly generated isolate of $F$. fujikuroi expressing green fluorescent protein (GFP). The amounts of $F$. fujikuroi in consecutive 3-cm segments of the whole plant were precisely quantified by SYBR green-based qPCR. The effect of GA sensitivity on resistance or susceptibility was also investigated.

\section{MATERIALS AND METHODS}

Plant materials. Artificially inoculated seedlings and naturally infected adult field plants were used for microscopic observation and qPCR analysis in this study. Inoculations were conducted using a susceptible cultivar, Zerawchanica karatals (ZK), and a resistant cultivar, Tainung 67 (TNG67). These two cultivars were selected from the Rice Diversity Panel 1 (Ali et al. 2011; Eizenga et al. 2014) based on their consistent susceptibility and resistance performance in repeated experiments performed by Chen et al. (2019). Seeds were provided by Ming-Hsin Lai and Dong-Hong Wu at the Crop Science Division, Taiwan Agricultural Research Institute. Field samples of three commercial cultivars, KH139, TK2, and Tainan 11 (TN11), were collected from Taitung and Taichung from March to May 2019 (Table 1). Plants of an unknown cultivar at the booting stage were also collected from Kangding, Pingtung on 17 April 2019. These field plants were collected between the late tillering and milk stages. The plants were 30 to $84 \mathrm{~cm}$ in height, with three to six nodes on the stem.

Inoculation of $\boldsymbol{F}$. fujikuroi. F. fujikuroi preserved on dry filter paper was gently smeared on half-strength potato dextrose agar (1/2 PDA) (19.5 g of PDA [HiMedia, India] and $7.5 \mathrm{~g}$ of agar [BioShop, Canada] per 1 liter) and cultured for 4 to 7 days at $25^{\circ} \mathrm{C}$ under a 12/ 12-h light/dark photoperiod. The spores were collected in sterile distilled water using a sterile tip, filtered through Kimwipes (Kimtech Science, U.S.A.), and then adjusted to $1 \times 10^{5}$ spores $/ \mathrm{ml}$ for inoculation (a few plants used for microscopic examination were inoculated with $1 \times 10^{6}$ spores $/ \mathrm{ml}$ ). Rice seeds were immersed in $60^{\circ} \mathrm{C}$ sterile distilled water for $10 \mathrm{~min}$ for sterilization, and then soaked in sterile distilled water (replaced every day) for 4 days at a temperature of $32^{\circ} \mathrm{C} / 28^{\circ} \mathrm{C}$ day/night. The germinated seeds were

TABLE 1. Adult field plants used in this study

\begin{tabular}{|c|c|c|c|c|c|c|c|c|}
\hline \multirow[b]{2}{*}{ Cultivar } & \multirow[b]{2}{*}{ Plant ID ${ }^{\mathrm{a}}$} & \multicolumn{2}{|r|}{$\mathrm{qPCR}^{\mathrm{b}}$} & \multirow[b]{2}{*}{$\begin{array}{l}\text { Number of } \\
\text { nodes }^{\mathrm{c}}\end{array}$} & \multirow[b]{2}{*}{$\begin{array}{l}\text { Number of nodes with } \\
\text { adventitious roots }^{c}\end{array}$} & \multirow[b]{2}{*}{ Collection site } & \multirow[b]{2}{*}{ Collection date } & \multirow[b]{2}{*}{ Growth stage } \\
\hline & & $\begin{array}{c}3 \mathrm{~cm} \\
\text { segment }\end{array}$ & $\begin{array}{l}\text { Node and nearby } \\
\text { internodes }\end{array}$ & & & & & \\
\hline \multirow[t]{8}{*}{ Kaohsiung 139} & KH139-1-1 & $\mathrm{V}$ & & - & 0 & Chishang, Taitung & 2019-03-28 & Late tillering \\
\hline & KH139-2-1 & $\mathrm{V}$ & & - & 0 & & & \\
\hline & KH139-3-1 & $\mathrm{V}$ & & 5 & 3 & Chishang, Taitung & $2019-05-23$ & Milk \\
\hline & KH139-3-2 & $\mathrm{V}$ & & 5 & 4 & & & \\
\hline & KH139-4-1 & $\mathrm{V}$ & & 4 & 3 & & & \\
\hline & KH139-5-1 & & V & 3 & 1 & & & \\
\hline & KH139-5-2 & & $\mathrm{V}$ & 4 & 3 & & & \\
\hline & KH139-6-1 & & $\mathrm{V}$ & 3 & 2 & & & \\
\hline \multirow[t]{9}{*}{ Tainan 11} & TN11-1-1 & & $\mathrm{V}$ & 5 & 4 & Holi, Taichung (field 1) & 2019-05-08 & Heading \\
\hline & TN11-2-1 & & $\mathrm{V}$ & 6 & 3 & & & \\
\hline & TN11-3-1 & & $\mathrm{V}$ & 4 & 2 & Holi, Taichung (field 2) & 2019-05-08 & Heading \\
\hline & TN11-4-1 & & $\mathrm{V}$ & 4 & 3 & & & \\
\hline & TN11-5-1 & $\mathrm{V}$ & & 5 & 2 & Holi, Taichung (field 1) & 2019-05-24 & Milk \\
\hline & TN11-5-2 & $\mathrm{V}$ & & 6 & 5 & & & \\
\hline & TN11-6-1 & $\mathrm{V}$ & & 5 & 2 & & & \\
\hline & TN11-6-2 & $\mathrm{V}$ & & 4 & 4 & & & \\
\hline & TN11-7-1 & $\mathrm{V}$ & & 5 & 4 & & & \\
\hline \multirow[t]{2}{*}{ Taikeng 2} & TK2-1-1 & $\mathrm{V}$ & & - & - & Guanshan, Taitung & 2019-04-08 & Late tillering \\
\hline & TK2-2-1 & $\mathrm{V}$ & & - & - & & & \\
\hline
\end{tabular}


soaked in the spore suspension or sterile distilled water (control) and shaken overnight (14 to $18 \mathrm{~h}$ ). The inoculated seeds were transplanted into 288-cell plug trays filled with Akadama soil (one seed per cell; each cell was $\mathrm{L} \times \mathrm{W} \times \mathrm{H}=1.75 \times 1.75 \times 2.54 \mathrm{~cm})$ and cultivated in a growth chamber $\left(32^{\circ} \mathrm{C} / 28^{\circ} \mathrm{C}\right.$ day/night temperature, 12/12-h light/dark photoperiod, luminous intensity 7,000 to $8,000 \mathrm{~lx}$ ). Bakanae disease severity was evaluated at 21 days postinoculation (dpi) using a 0 to 3 rating scale, and the overall disease severity index was calculated (Chen et al. 2015). The rating scale was defined as follows: $0=$ no symptoms; $1=$ seedling showing one of the following symptoms: stem or internode elongation, large leaf angle, or slenderness and paleness; $2=$ seedling showing complex symptoms; and $3=$ seedling death (Chen et al. 2015). The height of each plant was measured (from the base to top of the aerial part). For each cultivar, F. fujikuroi-induced elongation was calculated as: the height of the diseased plant minus the average height of the mock-inoculated plants. Phenotypic differences were analyzed by Tukey's honestly significant difference test at $P<0.05$ using GraphPad Prism version 7 (GraphPad Software).

Generation of a GFP-expressing strain of $\boldsymbol{F}$. fujikuroi. Plasmid pPK2HPHGFP (Michielse et al. 2009) carrying the GFP gene was provided by Ying-Lien Chen from the Department of Plant Pathology and Microbiology, National Taiwan University. Protoplasts of F. fujikuroi isolate Ff266 (Chen et al. 2016; GenBank accession numbers MT431665 and MT431666) were prepared and used for polyethylene glycol-mediated transformation following the protocols of Hou et al. (2002). Briefly, $10 \mu \mathrm{g}$ of pPK2HPHGFP linearized with HindIII was mixed with $200 \mu \mathrm{l}$ of protoplast suspension $\left(10^{7}\right.$ to $10^{8}$ protoplasts $\left./ \mathrm{ml}\right)$. Transformed protoplasts were regenerated on TB3 medium $(0.3 \%$, wt $/ \mathrm{vol}$, yeast extract; $0.3 \%$, wt/vol, casamino acids; and $20 \%$, wt/vol, sucrose) containing $0.7 \%$ (wt/vol) low melting agarose and hygromycin at $250 \mu \mathrm{g} / \mathrm{ml}$. Randomly selected transformants were cultured on V8 medium (20\%, wt/vol, V8 juice; $0.2 \%$, wt/vol, $\mathrm{CaCO}_{3}$; and $1.5 \%$, wt/vol, agar) containing hygromycin at $250 \mu \mathrm{g} / \mathrm{ml}$ for three successive generations, and then subjected to single spore isolation. The transformants were checked for fluorescence intensity under a fluorescence microscope (Olympus BX53) and evaluated for virulence by inoculating ZK and TNG67. Inoculation and disease evaluation were conducted as described above in three independent trials, with 10 plants per cultivar per transformant in each trial. One of the transformants, F. fujikuroi G3-1, was chosen for subsequent experiments.

Hand sectioning and microscopic examination. Hand-cut cross sections and longitudinal sections of different tissues were examined under a fluorescence microscope (OLYMPUS BX53), either under bright field or with a U-MWIBA3 filter (OLYMPUS, excitation filter 460 to $495 \mathrm{~nm}$, barrier filter 510 to $550 \mathrm{~nm}$ ) for GFP detection. Microscopic observation was conducted using infected seedlings collected at 0 to $33 \mathrm{dpi}$ from five independent inoculation trials. In each trial, one to three plants were sampled per day, and 20 to 60 evenly distributed cross sections per tissue sample (stem, root, embryo, and leaf) were examined per plant. In one of the trials, 10 longitudinal sections per tissue sample were examined. Hand sectioning and microscopy were also conducted on 15 adult field plants: 13 plants collected from the four fields listed in Table 1, as well as two plants (unknown cultivars at the booting stage) collected from Kangding, Pingtung on 17 April 2019. From each field at each collection time, two to three plants were sampled, and 100 to 160 cross sections of the stem and $\sim 20$ cross sections of the leaves were examined for each plant. Longitudinal and cross sectioning were also performed to check for internal discoloration, using an additional two KH139 plants (heading stage) collected from Chishang, Taitung on $28 \mathrm{March} 2019$. Some sections were stained with $0.1 \%$ (wt/vol) trypan blue staining solution (trypan blue in a 2:1:1 mixture of lactic acid, glycerol, and distilled water) for $7 \mathrm{~min}$ and de-stained with a 1:1 solution of glycerol and $0.3 \mathrm{M} \mathrm{HCl}$ (Roth et al. 2018).
DNA extraction. $F$. fujikuroi mycelium or rice tissues were collected in a $2-\mathrm{ml}$ microtube with two stainless steel beads (5/32inch diameter) and stored at $-80^{\circ} \mathrm{C}$. The sample was homogenized using a 2010 Geno/Grinder (SPEX SamplePrep). Genomic DNA was extracted from $F$. fujikuroi and rice following a standard cetyltrimethylammonium bromide extraction protocol (Doyle and Doyle 1987). A NanoDrop ND-1000 spectrophotometer (Thermo Scientific) was used to determine the quality and quantity of DNA.

Quantification of $\boldsymbol{F}$. fujikuroi by qPCR. Each $\mathrm{qPCR}$ reaction contained $6 \mu \mathrm{l}$ of Fast SYBR Green Master Mix (2×) (Applied Biosystems), $0.5 \mu \mathrm{M}$ forward and reverse primers, and 100 or $25 \mathrm{ng}$ DNA in a total volume of $12 \mu \mathrm{l}$. DNA ( $100 \mathrm{ng}$ ) was used for qPCR analysis of the aerial parts and roots of seedlings and the aerial parts of the adult plant; $25 \mathrm{ng}$ of DNA was used for the seedling root samples because the amount of DNA that could be extracted from the $3-\mathrm{cm}$ segment samples (described below) was only $1 / 3$ to $1 / 8$ that extracted from the aerial parts of the seedlings. The primers TqF2 (5'-GGCGCGTTTTGCCCTTTCCT-3') and TqR (5'-AGCGGCTTCCTATTGTCGAA-3') targeting the translation elongation factor $1-\alpha$ gene in $F$. fujikuroi (Carneiro et al. 2017) were used. Amplification was performed in three technical replicates with the StepOnePlus Real-Time PCR System (Applied Biosystems). The thermal cycling parameters were 1 cycle of $95^{\circ} \mathrm{C}$ for $20 \mathrm{~s}$ followed by 40 cycles of $95^{\circ} \mathrm{C}$ for $3 \mathrm{~s}$ and $60^{\circ} \mathrm{C}$ for $30 \mathrm{~s}$. Standard curves were generated for inoculated seedlings by mixing healthy plant DNA (extracted from the aerial parts) and a fivefold serial dilution of $F$. fujikuroi G3-1 DNA (10 ng to $0.0032 \mathrm{ng}$ ) with a total of $100 \mathrm{ng}$ of DNA per reaction. For adult field plants, standard curves were generated by mixing healthy plant DNA (extracted from the aerial parts) and a fivefold serial dilution of $F$. fujikuroi Ff266 (50 to $0.016 \mathrm{ng}$ ), with a total of $100 \mathrm{ng}$ of DNA per reaction.

The amounts of $F$. fujikuroi in different parts of the inoculated seedlings were quantified by qPCR. Four independent inoculation trials were conducted, with three plants per cultivar per time point. In trials one and two, consecutive 3 -cm segments of the whole plant were collected at 3, 7, 10,14, 17, and $21 \mathrm{dpi}$. In trials three and four, the embryo and the first 0 - to $3-\mathrm{cm}$ segments of the base of the aerial part and basal roots were collected at 7, 14, and $21 \mathrm{dpi}$. In the first trial, the embryo was cut into half and combined with the first 0- to $3-\mathrm{cm}$ segment of the basal root and the base of the aerial part. To understand the precise distribution of $F$. fujikuroi, the embryo, stem, and root were collected separately in trials two to four. Differences among the quantities of $F$. fujikuroi in different segments of $\mathrm{ZK}$ or TNG67 at different time points were analyzed by Tukey's honestly significant difference test at $P<0.05$ using GraphPad Prism version 7 (GraphPad Software). Pearson correlation analysis was used to analyze the correlation between seedling height and total biomass index (defined as the sum of the amount of $F$. fujikuroi $[\mathrm{ng} / 100 \mathrm{ng}$ of total DNA] in all the segments of a plant).

qPCR was also used to quantify the amounts of $F$. fujikuroi in consecutive $3-\mathrm{cm}$ segments of 12 adult field plants (Table 1). To determine the distribution of $F$. fujikuroi in nodes, internodes, and adventitious roots, qPCR analysis was conducted for each node, the 0 to $1 \mathrm{~cm}$ and 1 - to 2 -cm-internode segments above/below the node, and the emerged adventitious roots of seven plants (Table 1).

Gibberellic acid treatment. Rice seeds were immersed in $60^{\circ} \mathrm{C}$ sterile distilled water for $10 \mathrm{~min}$ for sterilization, and then soaked in sterile distilled water (replaced every day) for 4 days at $32^{\circ} \mathrm{C}$ day $/ 28^{\circ} \mathrm{C}$ night. Germinated seeds were treated with gibberellic acid-3 $\left(\mathrm{GA}_{3}\right)$ at $0.01,0.5$, or $25 \mathrm{mg} /$ liter according to the method of Ma et al. (2008). Seeds immersed in sterile distilled water were used as a control (mock treatment). After $16 \mathrm{~h}$ of incubation at room temperature, the seeds were sown in pots $(\mathrm{L} \times \mathrm{W} \times \mathrm{H}=3.5 \times$ $3.5 \times 4.5 \mathrm{~cm})$ containing Akadama soil. Seedling heights were measured 14 days after treatment. The experiment was conducted in three independent trials, each with 10 seedlings per cultivar per treatment. Student's $t$ test was performed to analyze the height differences between $\mathrm{GA}_{3}$ - and mock-treated seedlings. 


\section{RESULTS}

Generation of a fluorescent $F$. fujikuroi isolate, G3-1. The mycelia and spores of $F$. fujikuroi G3-1 consistently exhibited bright green fluorescence (Fig. 1A). The morphological characteristics of G3-1 were similar to those of the wild-type strain Ff266. Both isolates formed orange to pink colonies on 1/2 PDA (Fig. 1B). ZK and TNG67 inoculated with F. fujikuroi G3-1 and Ff266 showed typical bakanae symptoms including elongated stems and leaves and a wider leaf angle (Fig. 1C). In susceptible ZK, no significant difference was found between the disease severity indexes of plants infected by G3-1 (53.6\%) and Ff266 (60.3\%). TNG67 plants infected with G3-1 had a lower disease severity index (7.1\%) than those infected with Ff266 (23.6\%) (Fig. 1D).

Colonization patterns of $F$. fujikuroi in rice seedlings. Two types of $F$. fujikuroi colonization patterns were observed in both seedlings and adult plants. The hyphae aggregated (Fig. 2A) or grew around the cells (Fig. 2B). Both intracellular (Fig. 2C) and intercellular (Fig. 2D) hyphal extension were observed in shoot and root tissues. In a few sections, the hyphae were found to constrict before moving to the adjacent cell (Fig. 2E).

Pathogenesis of $\boldsymbol{F}$. fujikuroi in rice seedlings. Sections of the leaves, roots, stems, and embryos of inoculated ZK and TNG67 were examined at different time points. F. fujikuroi spores were found to attach on the leaf surface at 1 to $3 \mathrm{dpi}$. However, from over 1,000 sections examined, leaf infection was not observed until 21 dpi. In root tissues, the $F$. fujikuroi infection process was similar in susceptible ZK and resistant TNG67. F. fujikuroi spores attached on the root surface at 1 to $3 \mathrm{dpi}$ (Fig. 3A) and invaded the epidermis at 3 to 5 dpi (Fig. 3B). The hyphae penetrated the exodermis and sclerenchyma layer at 6 to $8 \mathrm{dpi}$ (Fig. 3C) and grew toward the central cylinder (Fig. 3D). The mesodermis was colonized at $\sim 14$ dpi (Fig. 3E), then the hyphae penetrated the endodermis and proliferated in the vascular bundle after $21 \mathrm{dpi}$ (Fig. 3F; the phenomenon was generally observed, but here we present a more clear and representative image from a ZK seedling inoculated with $10^{6}$ [instead of $10^{5}$ ] F. fujikuroi spores/ml). The infection was first observed mainly in the root tissues near the embryo. Later on, the hyphae spread to the entire root system but only a few hyphae were found in the root tips and lateral roots.

In the stem, a slight delay in initial infection and colonization of F. fujikuroi was observed in resistant TNG67. The spores germinated then invaded the surface of the basal stem (Fig. 3G) at 1 to $3 \mathrm{dpi}$ and 1 to $7 \mathrm{dpi}$ in ZK and TNG67, respectively. The hyphae then developed in the stem tissues (Fig. 3H to J) from 7 to $14 \mathrm{dpi}$ and 10 to 14 dpi in ZK and TNG67, respectively. In both cultivars, the

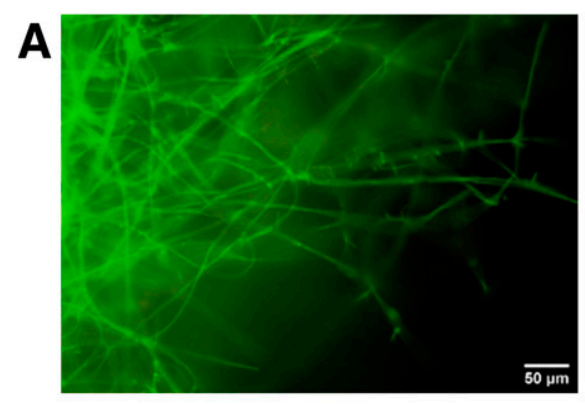

B

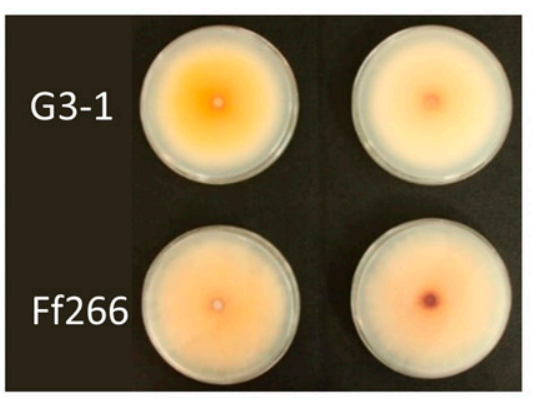

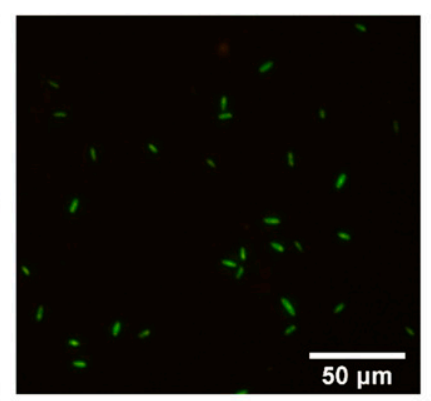

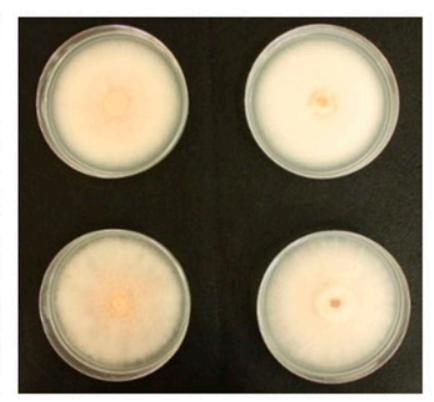

D

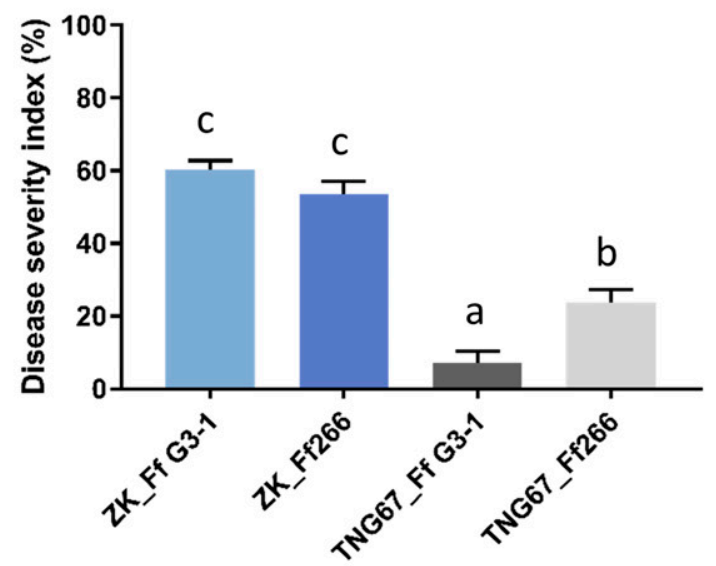

Rice cultivars inoculated with wild type and fluorescent $F$. fujikuro $i$ isolates
C

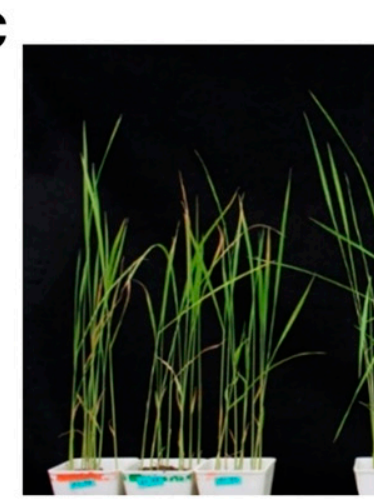

CK
ZK

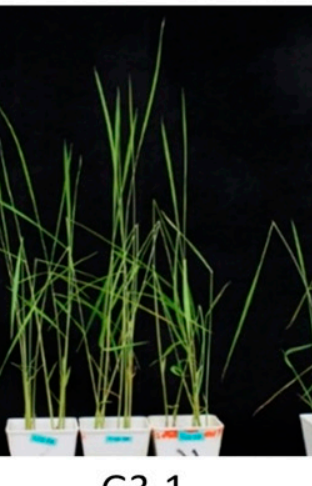

G3-1

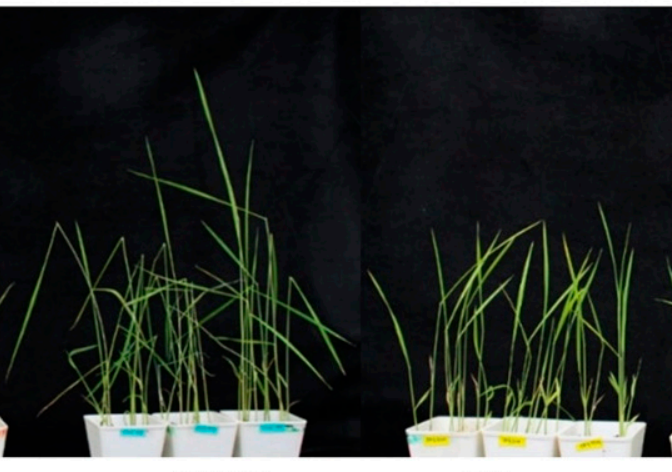

CK

Ff266
TNG67

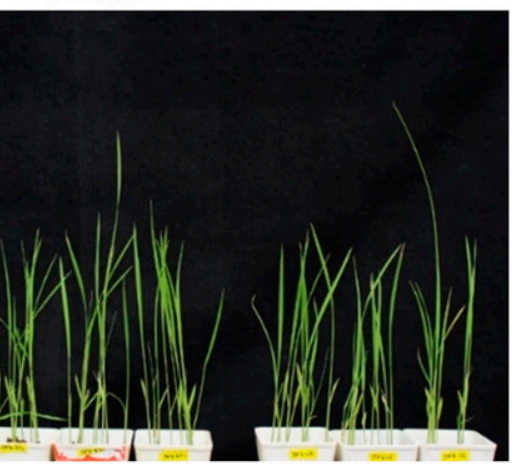

G3-1

Ff266

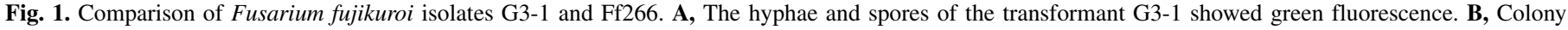

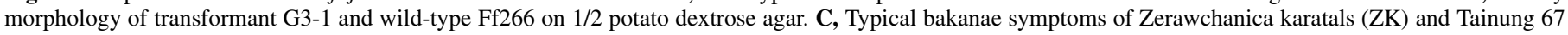

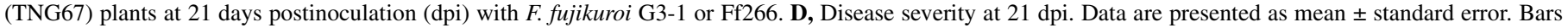
labeled with different letters are significantly different as determined by Tukey's honestly significant difference test at $P<0.05$. 
epidermal and ground tissues of coleoptile were destroyed by a mass of hyphae after 17 to 20 dpi (Fig. 3K). Although the hyphae heavily colonized the basal stem, the pathogen was absent from the surrounding leaf sheath (Fig. 3L; the phenomenon was generally observed, but here we present a more clear and representative image from a ZK seedling inoculated with $10^{6} \mathrm{~F}$. fujikuroi spores $/ \mathrm{ml}$ ). Until $21 \mathrm{dpi}$, F. fujikuroi was mainly restricted to within $\sim 3 \mathrm{~cm}$ from the base in both cultivars.

In the embryo, no difference was observed in the infection and colonization of ZK and TNG67 by F. fujikuroi. Only a few hyphae colonized the embryo tissues at 1 to $3 \mathrm{dpi}$. An expanding hyphal network was formed at 7 to $10 \mathrm{dpi}$ (Fig. $3 \mathrm{M}$ and N), and the embryo was fully colonized after 14 dpi (Fig. 3O).

Distribution of $F$. fujikuroi in rice seedlings. The coefficient of determination $\left(R^{2}\right)$ values for qPCR standard curves for ZK and TNG67 (Supplementary Fig. S1A) and for KH139, TK2, and TN11 (Supplementary Fig. S1B) were all >0.99. In repeated qPCR assays, F. fujikuroi DNA was detected specifically (based on melting curve analysis) and quantified accurately at a minimum concentration of $0.016 \mathrm{ng}$ per $100 \mathrm{ng}$ of total DNA, with a threshold cycle around 33 to 34 . Therefore, F. fujikuroi was determined to be undetectable when the estimated amount was below $0.016 \mathrm{ng}$ in this study.

The distribution of $F$. fujikuroi in ZK and TNG67 seedlings was evaluated by qPCR at 3, 7, 10,14, 17, and $21 \mathrm{dpi}$. The results from inoculation trial 1 (Supplementary Fig. S2) and trial 2 (Fig. 4A) showed that in both ZK and TNG67, F. fujikuroi primarily infected the embryo and the first 0 - to 3-cm segment of basal roots (R1) and the base of the aerial part (A1; containing only stem tissues) from 0 to 21 dpi. In general, F. fujikuroi was detected first in R1 and the embryo at $3 \mathrm{dpi}$, and then in A1 at $7 \mathrm{dpi}$ (Fig. 4A). After $14 \mathrm{dpi}$, small amounts of $F$. fujikuroi ( 0.016 to $1.78 \mathrm{ng}$ ) were detected along the roots and occasionally in different segments of the aerial part of the plant (Fig. 4A). Great variation in the amount of F. fujikuroi was observed among individual plants. In inoculation trials one and two, elongation symptoms were first observed in $\mathrm{ZK}$ at $10 \mathrm{dpi}$, and in TNG67 at 14 dpi (Supplementary Fig. S3A). The elongation growth of infected ZK and TNG67 at $14 \mathrm{dpi}$ and $21 \mathrm{dpi}$ was not significantly correlated with the total biomass of $F$. fujikuroi in the whole plant (Supplementary Fig. S3B).

To assess the tissue and cultivar preference of $F$. fujikuroi, the quantities of F. fujikuroi in R1, A1, and the embryo at 7, 14, and 21 dpi were examined in two additional trials (Fig. 4B). Based on combined data from inoculation trials two and four, no significant difference was found between $\mathrm{R} 1$ and $\mathrm{A} 1$ or between $\mathrm{ZK}$ and TNG67 at all three time points. Compared with R1 and A1, the embryo contained a similar amount of $F$. fujikuroi at $7 \mathrm{dpi}$ and significantly higher amounts of $F$. fujikuroi at 14 and $21 \mathrm{dpi}$. The amount of $F$. fujikuroi in the embryo greatly increased from $0.69 \mathrm{ng}$ at $7 \mathrm{dpi}$ to $14.3 \mathrm{ng}$ at $14 \mathrm{dpi}$ in $\mathrm{ZK}$, and from $4.38 \mathrm{ng}$ at $14 \mathrm{dpi}$ to $12.24 \mathrm{ng}$ at $21 \mathrm{dpi}$ in TNG67.

Sensitivity of ZK and TNG67 to GA $\mathbf{A}_{3}$. To determine if the different symptoms of ZK and TNG67 were caused by different sensitivities to $\mathrm{GA}_{3}, \mathrm{GA}_{3}$-induced elongation growth was evaluated (Fig. 5). With the addition of $\mathrm{GA}_{3}$ at $0.01 \mathrm{mg} /$ liter, no difference was observed between $\mathrm{GA}_{3}$ - and mock-treated plants for both cultivars. Compared with the mock-treated controls, the heights of $\mathrm{ZK}$ seedlings increased by $24.6 \%(P<0.001)$ and $44.4 \%(P<0.001)$ with the addition of $\mathrm{GA}_{3}$ at 0.5 and $25 \mathrm{mg} / \mathrm{liter}$, respectively; the heights of TNG67 seedlings increased by $13.4 \%(P=0.015)$ and $51.4 \%(P<0.001)$ with the addition of $\mathrm{GA}_{3}$ at 0.5 and $25 \mathrm{mg} / \mathrm{liter}$, respectively. The height of $\mathrm{ZK}$ seedlings was affected to a greater extent than that of TNG67 seedlings under $\mathrm{GA}_{3}$ at $0.5 \mathrm{mg} / \mathrm{liter}$, which suggested that $\mathrm{ZK}$ was more sensitive to $\mathrm{GA}_{3}$.

Colonization patterns of $\boldsymbol{F}$. fujikuroi in adult field plants. An adult field plant (KH139) showing bakanae symptoms and one that was healthy in appearance were examined macroscopically.
A

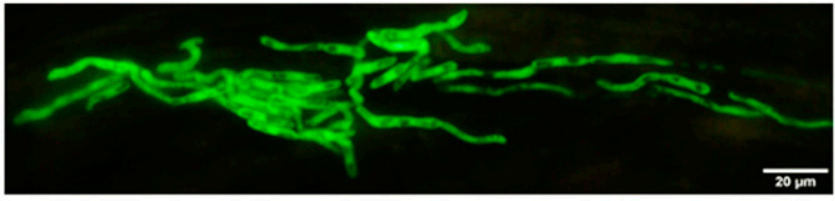

C

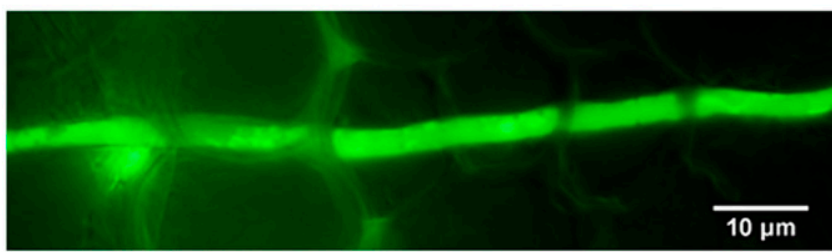

D

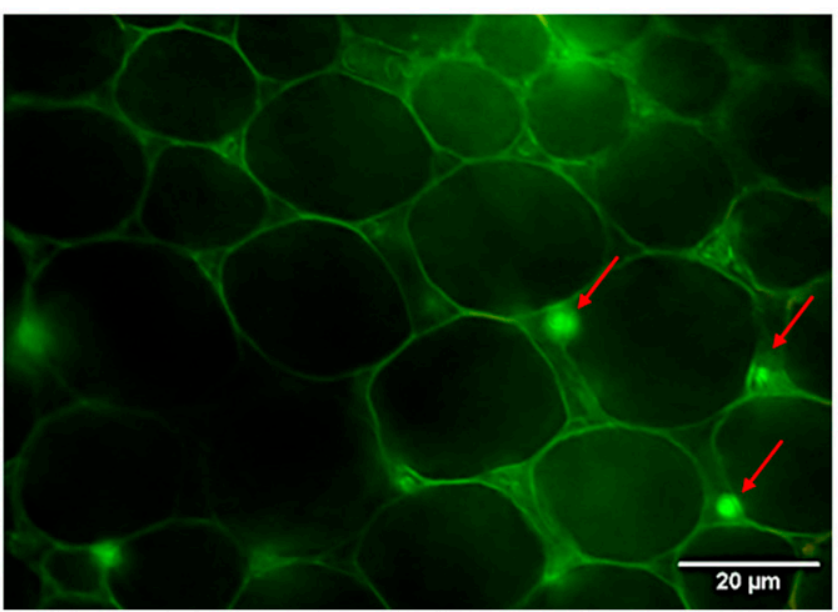

B

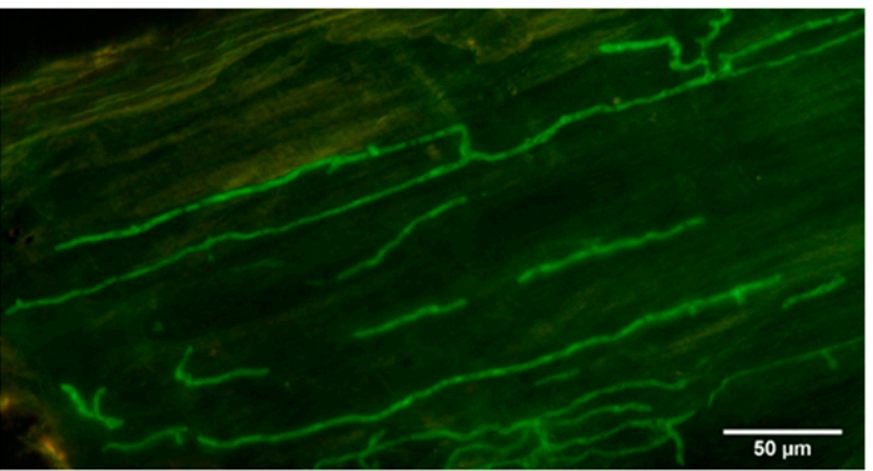

E

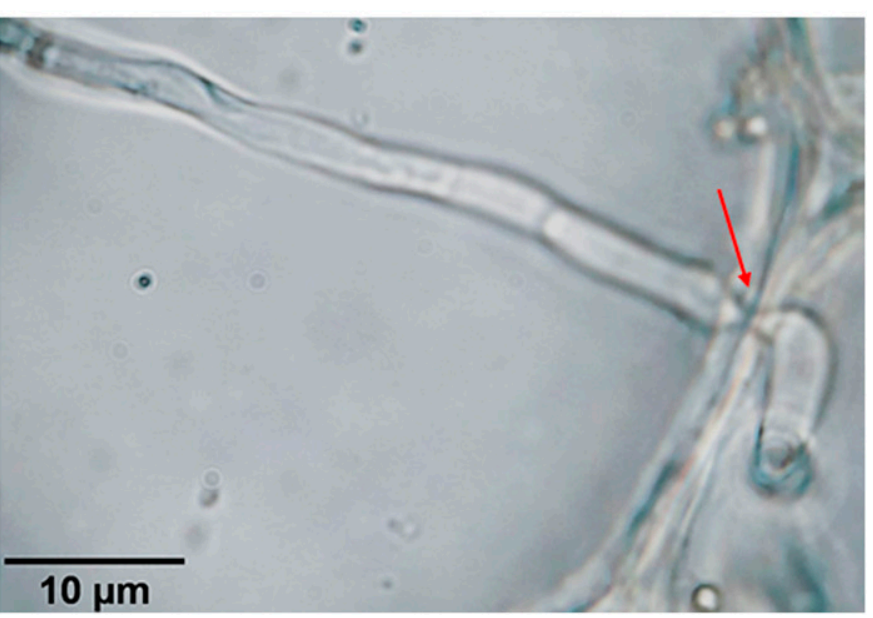

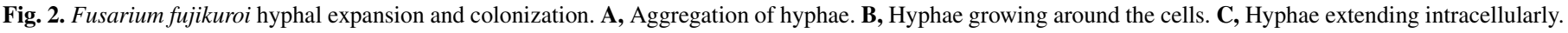
D, Intercellular hyphae (arrows). E, A hypha that constricted (arrow) when passing through the rice cell wall. 
Cross sectioning of a 0 - to $4-\mathrm{cm}$ segment at the base of the stem revealed that the surface and inner tissues were green in the healthy plant and partially necrotic in the diseased plant (Supplementary Fig. S4A). Longitudinal sectioning of a diseased plant showed discoloration in the lower node and internode segments. The upper part of the diseased plant remained green (Supplementary Fig. S4B). Whitish mycelia were observed in both the node and internode segments.

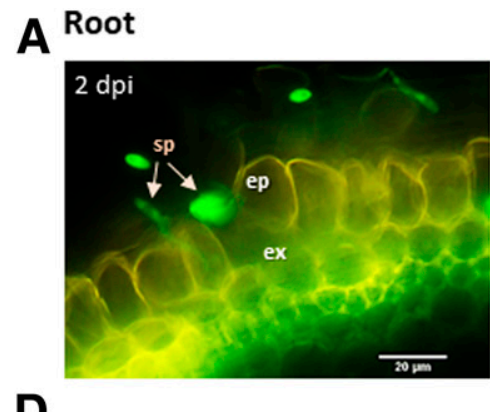

B

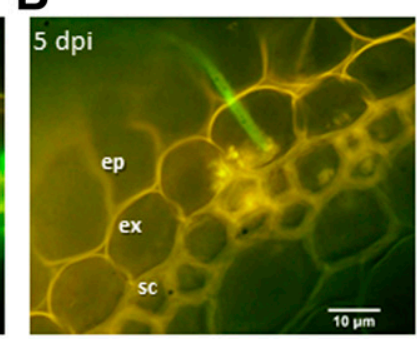

E
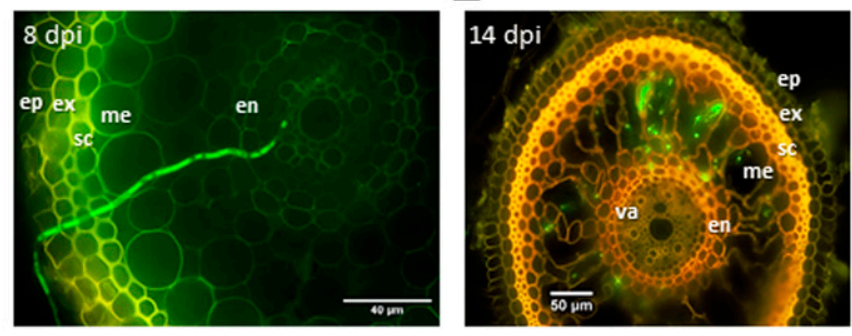

C

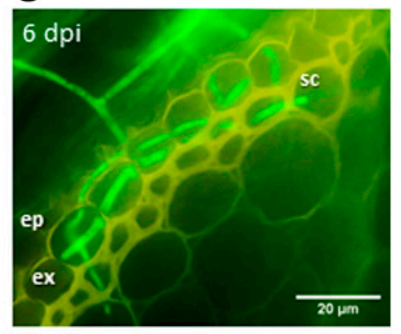

$\mathbf{F}$

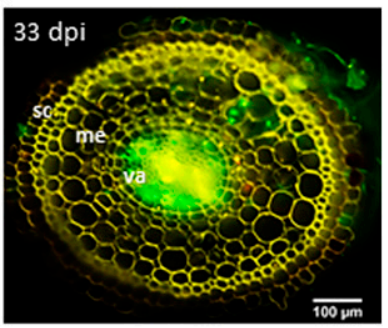

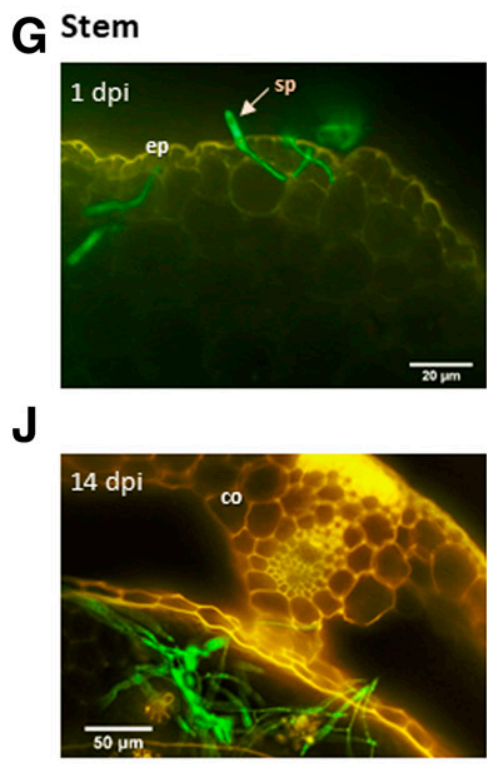

H
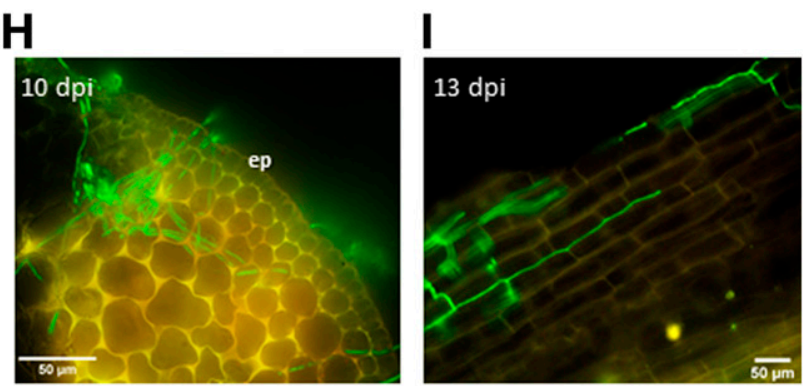

K

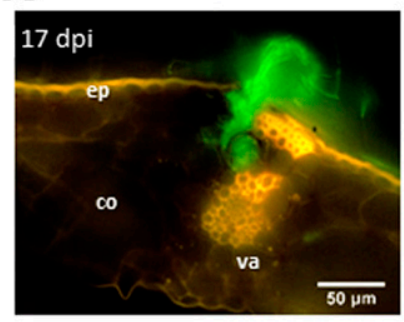

$\mathbf{L}$

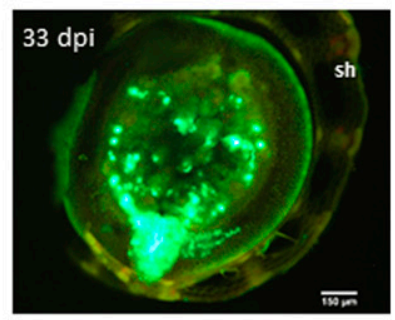

M Embryo

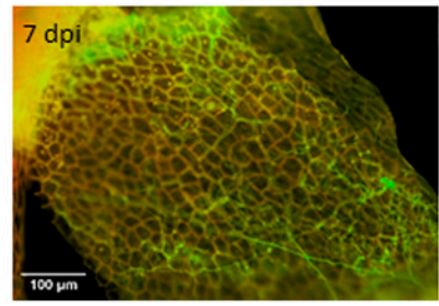

$\mathbf{N}$

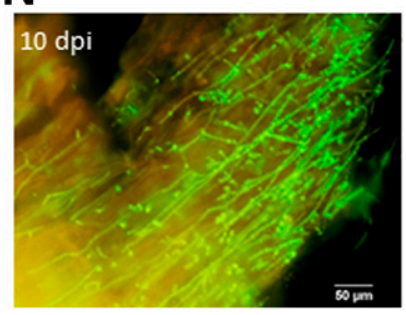

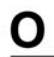

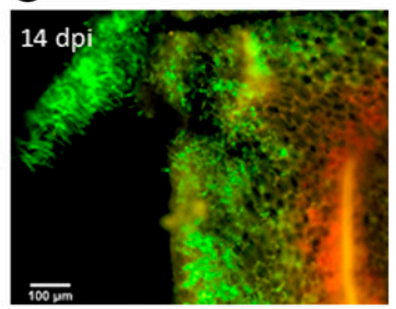

Fig. 3. Infection and colonization of rice seedlings by Fusarium fujikuroi. A to E, Pathogenesis of F. fujikuroi in the root. A, Spores adhering on the root surface. B, Hyphae penetrating the epidermis. C, Hyphae invading the exodermis and sclerenchyma layer. D, Hyphae growing toward the central cylinder. E, Hyphae colonizing the mesodermis and reaching the endodermis. F, Hyphae heavily colonizing the vascular cylinder. $\mathbf{G}$ to $\mathbf{L}$, Pathogenesis of $F$. fujikuroi in the basal stem. G, Infection starting from a spore attached to the stem surface. H to I, Hyphal proliferation in the ground tissues. J, Hyphal growth from the stem to surrounding coleoptile. K, A mass of hyphae destroyed the epidermis and ground tissues of the coleoptile. L, Hyphae heavily colonized the stem but not the surrounding leaf sheath. M to O, Expanding hyphae network in the embryo. Plant materials in A to D, F, H to I, K, L, and N: ZK; and E, G, J, M, and O: TNG67. Sections in F and L were from plants inoculated with $10^{6} \mathrm{~F}$. fujikuroi spores $/ \mathrm{ml}$, and the rest of the sections were from plants inoculated with $10^{5} \mathrm{~F}$. fujikuroi spores $/ \mathrm{ml}$. co, coleoptile; en, endodermis; ep, epidermis; ex, exodermis; sp, spore; me, mesodermis; sc, sclerenchyma layer; sh, leaf sheath; and va, vascular bundle. 
In symptomatic plants of the KH139, TK2, and TN11 cultivars between the late tillering and milk stages, $F$. fujikuroi colonization was found mainly within the vascular bundles in both the roots and stem (Fig. 6C, D, F, G, and I). The hyphae were observed in the xylem vessels of the root (Fig. 6C and D). In the stem, F. fujikuroi colonized the xylem vessels, phloem vessels, and air space of central vascular bundles (Fig. $6 \mathrm{~F}$ and $\mathrm{G}$ ) and small vascular bundles (Fig. 6I). Browning was observed in some vascular bundles (Fig. $6 \mathrm{G}$ ). Leaves were almost free of the pathogen. F. fujikuroi hyphae were observed in the vascular bundle of the leaf (Fig. 6J), but only in
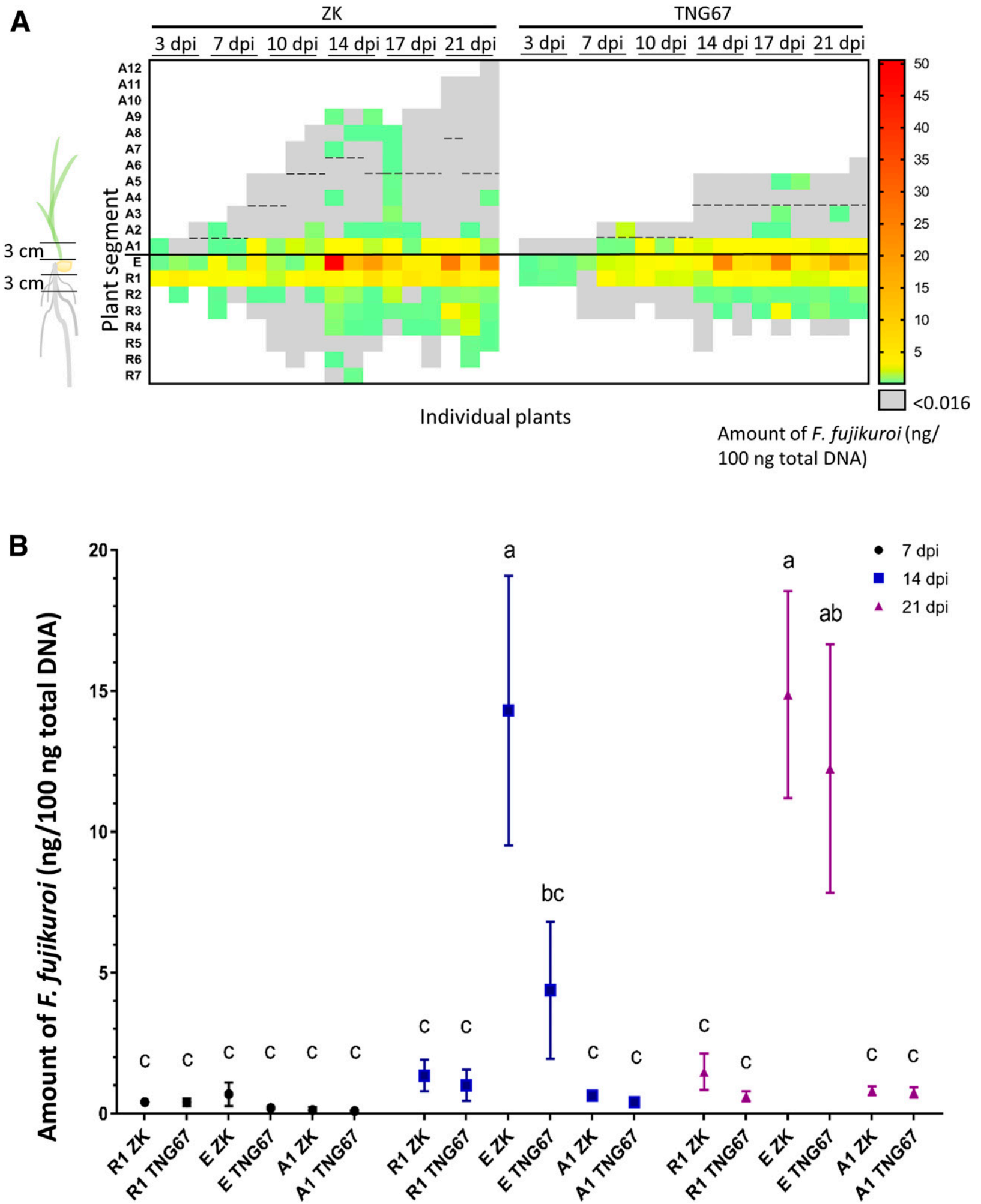

Fig. 4. qPCR analysis of the distribution of Fusarium fujikuroi in rice seedlings. A, The amounts of $F$. fujikuroi in consecutive 3-cm segments of Zerawchanica karatals (ZK) and Tainung 67 (TNG67) plants inoculated with F. fujikuroi G3-1 (inoculation trial 2). A\#, the segment number of the aerial part of the plant; R\#, the segment number of the root part; and E, embryo. The aerial segment A1 contains only stem tissues, the segments above the dashed line contain only leaf tissues, and the remaining aerial segments may contain both stem and leaf tissues. B, The amounts of $F$. fujikuroi in A1, R1, and the embryo of ZK and TNG67 (inoculation trials two to four). Data are presented as mean \pm standard error. Different letters indicate significant differences in means as determined by Tukey's honestly significant difference test at $P<0.05$. 
one out of 200 leaf sections examined in this study. In TN11 plants collected from two different fields in Holi, Taichung, the hyphae were found spreading out from vascular bundles to nearby parenchyma cells (Fig. 6K), which caused necrosis and browning of the parenchyma cells (Fig. 6L). Abundant hyphae and microconidia were also observed in the parenchyma (Fig. 6M).

Distribution of $\boldsymbol{F}$. fujikuroi in adult field plants. The longitudinal distributions of F. fujikuroi in KH139, TK2, and TN11 plants were evaluated by qPCR analysis. Among rice plants in the same hill, F. fujikuroi was undetectable in asymptomatic plants and detectable in the plants showing bakanae symptoms (data not shown). The distribution patterns shown in Figure 7A suggested that F. fujikuroi mainly colonized the lower parts of the diseased plants. $F$. fujikuroi was distributed unevenly along the plants, and the maximum colonization was detected at the middle of the $F$. fujikuroi-colonized aerial part rather than at the base of the infected plants.

qPCR was also performed to understand the pathogen distribution in each node, nearby internodes, and adventitious roots (Fig. 7B). In general, lower amounts of $F$. fujikuroi were detected in the node than in the nearby internodes $(1$ and $2 \mathrm{~cm}$ above/below the specific node). In some plants (i.e., KH139-5-1, KH139-6-1, TN113-1, and TN11-4-1) adventitious roots were present on nodes without detectable $F$. fujikuroi colonization. In addition, the plants showing more nodes with adventitious roots did not necessarily contain higher amounts of $F$. fujikuroi. Examples included KH1394-1 and TN11-5-1 (Fig. 7A) and TN11-4-1 (Fig. 7B).

\section{DISCUSSION}

This study combined light/fluorescent microscopy and qPCR analysis to qualitatively and quantitatively examine the pathogenesis and distribution of $F$. fujikuroi in rice. Time-course analysis of rice seedlings revealed that within $21 \mathrm{dpi}, F$. fujikuroi was largely confined to the embryo, basal stem, and basal roots. The remarkably high level of $F$. fujikuroi colonization in the embryo could be due to increased levels of nutrients (mainly sugars) derived from germinating rice seeds (Yu et al. 2015). The distribution pattern of F. fujikuroi hyphae in adult plants suggested that the pathogen expands vertically through vascular bundles. Notably, leaf infection was scarcely detected. We observed colonization of the vascular bundle of the leaf (Fig. 6J), and Nisikado and Kimura (1941) observed the presence of $F$. fujikuroi in the leaf sheath arising from the node where F. fujikuroi reached. Although the leaf does not serve as an initial infection site (Sun 1975), F. fujikuroi could extend systemically to the leaf at later stage of the disease. At both the seedling and adult stages, while great variation in $F$. fujikuroi biomass was found in different individual plants, $F$. fujikuroi was almost always detectable in the basal stem and basal roots, which makes these two sites good targets for pathogen isolation and investigation of direct interactions between rice and $F$. fujikuroi. Interestingly, while $F$. fujikuroi mainly colonized the stem within $3 \mathrm{~cm}$ from the base in seedlings, the maximum colonization of $F$. fujikuroi in adult field plants was found in the middle portion of the stem. One explanation for this might be that in the paddy field, the temperature and oxygen concentration in the rice tissues submerged under water may be relatively low (Setter et al. 1987). Whether these conditions are unfavorable for $F$. fujikuroi needs further investigation.

In the basal stem and roots of rice seedlings, the hyphae of $F$. fujikuroi were found to directly penetrate the epidermal cells at 3 to $6 \mathrm{dpi}$, extend in rice tissues through the formation of inter- and intracellular mycelium, then enter into and colonize the vascular bundles. We observed a slight delay in initial infection and colonization of $F$. fujikuroi in the stem tissues of TNG67 compared with those of ZK. This could be due to the resistance of TNG67 and/ or the reduced virulence of $F$. fujikuroi G3-1 on TNG67. In adult field plants, we observed occlusion of vascular bundles with hyphae and microconidia, and radial hyphal expansion from vascular bundles to surrounding parenchyma cells. The invasion and colonization patterns of $F$. fujikuroi, including direct hyphal penetration and expansion of hyphae inter- and intracellularly to invade xylem and phloem tissues, have been widely observed in other phytopathogenic Fusarium spp., such as F. oxysporum f. sp.
A
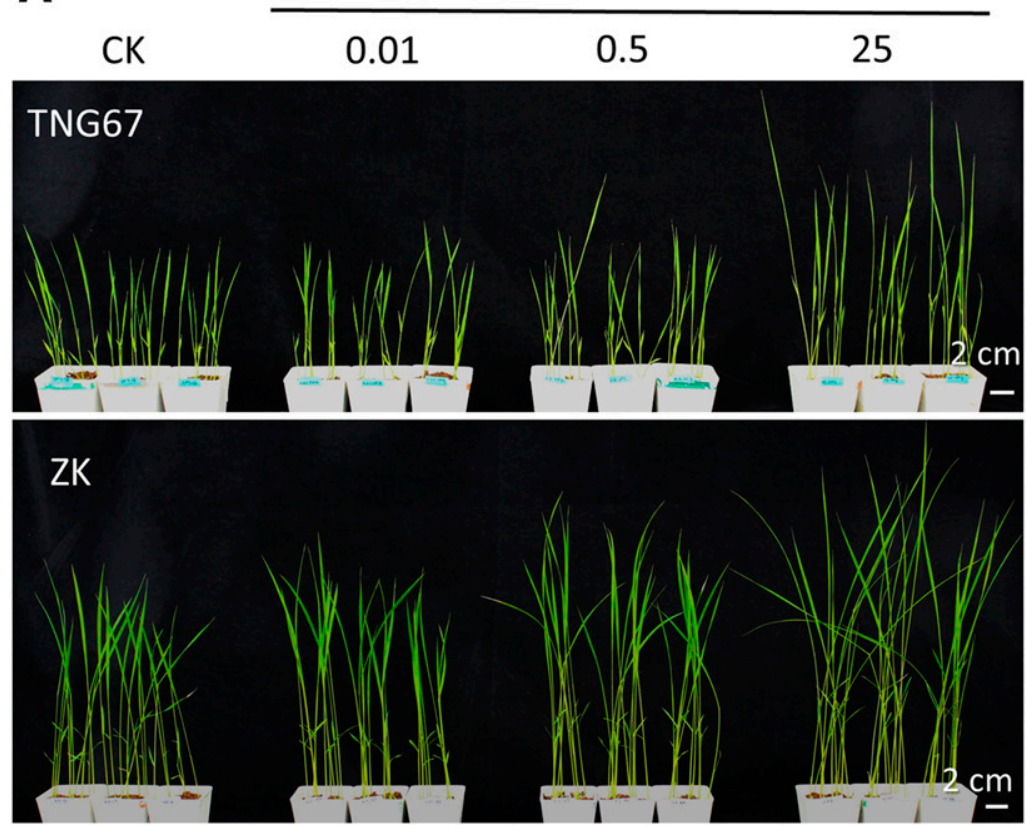

B

- $\mathrm{CK}$

- $0.01 \mathrm{mg} / \mathrm{l}$ of $\mathrm{GA}_{3}$

- $0.5 \mathrm{mg} / \mathrm{l}$ of $\mathrm{GA}_{3}$

> $25 \mathrm{mg} / \mathrm{l}$ of $\mathrm{GA}_{3}$

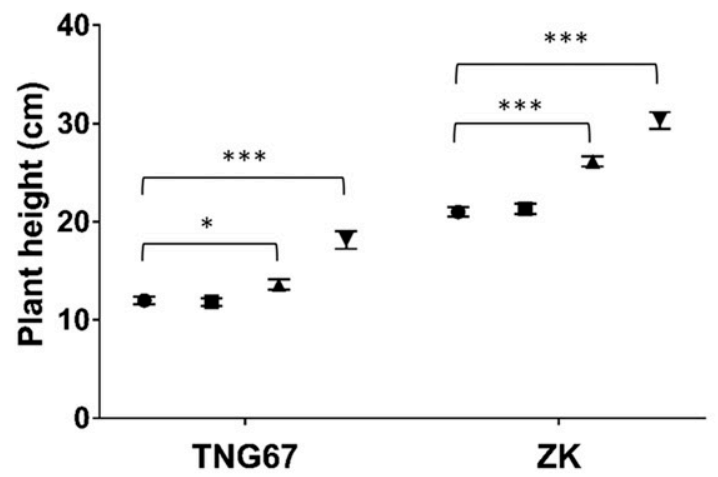

Fig. 5. Gibberellic acid-3 (GA3)-induced elongation growth of Zerawchanica karatals (ZK) and Tainung 67 (TNG67). A, Seeds of ZK and TNG67 were treated with three concentrations of $\mathrm{GA}_{3}\left(0.01,0.5\right.$, and $25 \mathrm{mg} /$ liter) and $\mathrm{ddH}_{2} \mathrm{O}(\mathrm{CK})$. Rice seedlings were photographed at 14 days posttreatment. B, Plant heights (mean \pm standard error) at 14 days posttreatment. Asterisks denote significant differences between $\mathrm{GA}_{3}$-treated and CK plants as determined by Student's $t$ test (*, 0.01 $<P<0.05 ; * *, 0.001<P<0.01 ;$ and $* * *, P<0.001)$. 
cubense causing Panama disease of banana (Dong et al. 2019), F. oxysporum f. sp. radicis-lycopersici causing tomato foot and root rot (Lagopodi et al. 2002), F. oxysporum f. sp. fragariae causing strawberry wilt (Fang et al. 2012), and F. graminearum causing head blight of wheat and root, stem, and ear rot of maize (Nguyen et al. 2016). Although appressoria and infection cushions were reported for F. graminearum (Boenisch and Schäfer 2011) and F. fujikuroi (Sunani et al. 2019), we did not observe any specialized infection
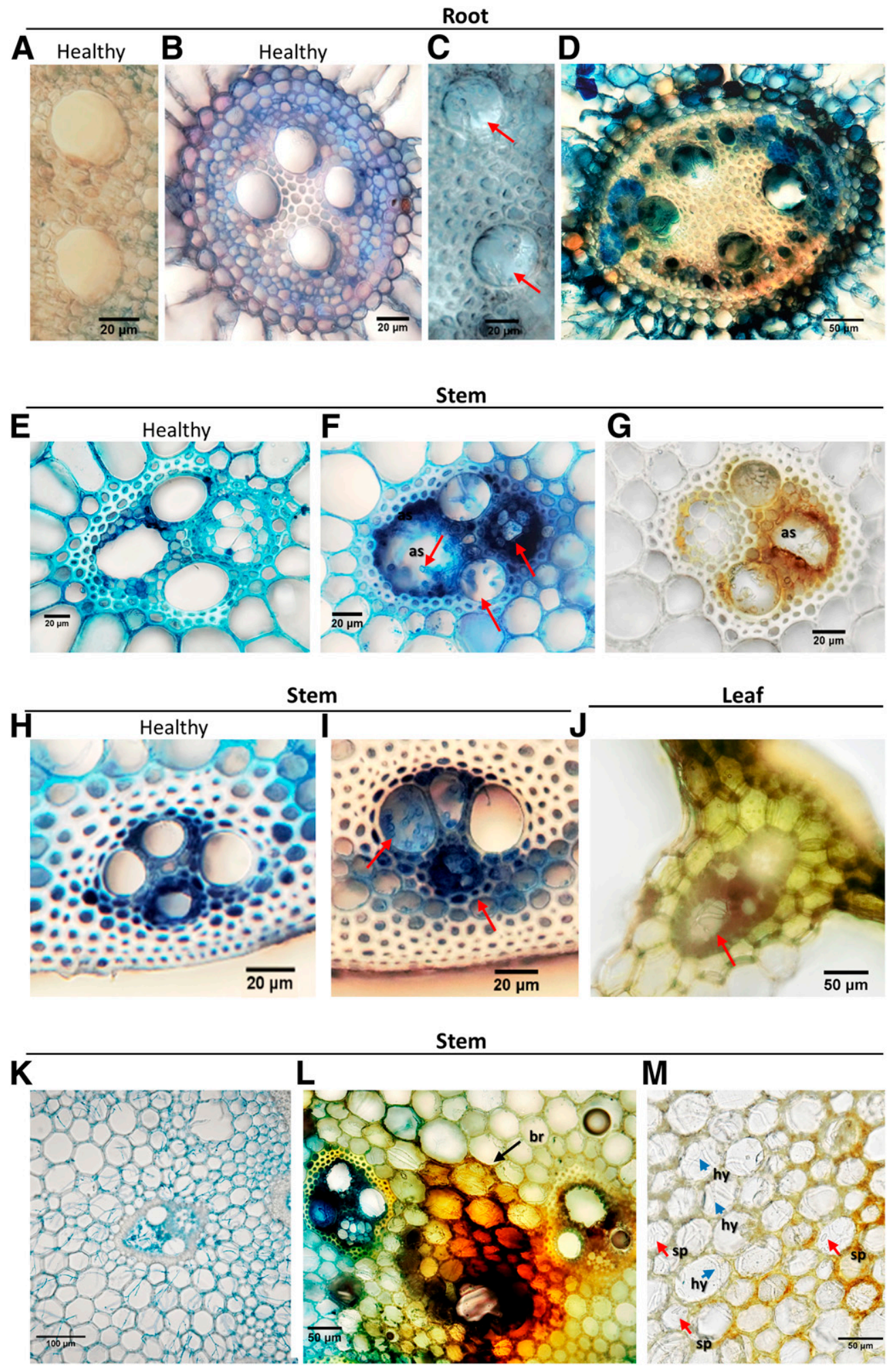

Fig. 6. Colonization of Fusarium fujikuroi in adult field plants. A and B, Clean xylem vessels in healthy root tissues without pathogen colonization. C, Hyphae (arrows) blocking the xylem vessels of the root tissues. D, Infected root tissues were partially brown. E, A healthy central vascular bundle in the stem. F, Hyphae (arrows) colonizing the xylem vessels, phloem vessels, and air space of central vascular bundles in the stem. G, A browning vascular bundle in the colonized stem. H, A healthy small vascular bundle in the stem. I, Hyphae blocking a small vascular bundle in the stem. J, Hyphae in the vascular bundle of the leaf. Leaf infection was observed in only one out of 200 leaf sections examined. K, Hyphae spreading out from the vascular bundle in the stem to nearby parenchyma cells. L, Necrosis and browning of infected parenchyma cells in the stem. M, Hyphae and microconidia in the parenchyma of the stem. Plant materials in A, C, E, and G to I are Tainan 11 plants collected from Holi, Taichung in April and May 2019; B and F are Kaohsiung 139 plants collected from Chishang, Taitung in March 2019; and D is an unknown cultivar collected from Kanding, Pingtung in April 2019. Samples in B, D, E, F, H, I, K, and L were stained with trypan blue. as, air space; br, browning; hy, hyphae; and sp, spore. 
structures despite careful examination. The discrepancy between our observations and the findings of Sunani et al. (2019) may be due to the different rice cultivars and microscopy techniques used.

Some intracellular hyphae of $F$. fujikuroi were found to be constricted when passing through the rice cell wall (Fig. 2E). The hyphae of rice blast fungus Magnaporthe oryzae were reported to constrict to $\sim 500 \mathrm{~nm}$ in diameter to cross the cell wall (Kankanala et al. 2007). Since plasmodesmatal channels in plants are 30 to $50 \mathrm{~nm}$ in diameter (Cook et al. 1997), Kankanala et al. (2007) hypothesized that $M$. oryzae might manipulate the structure of
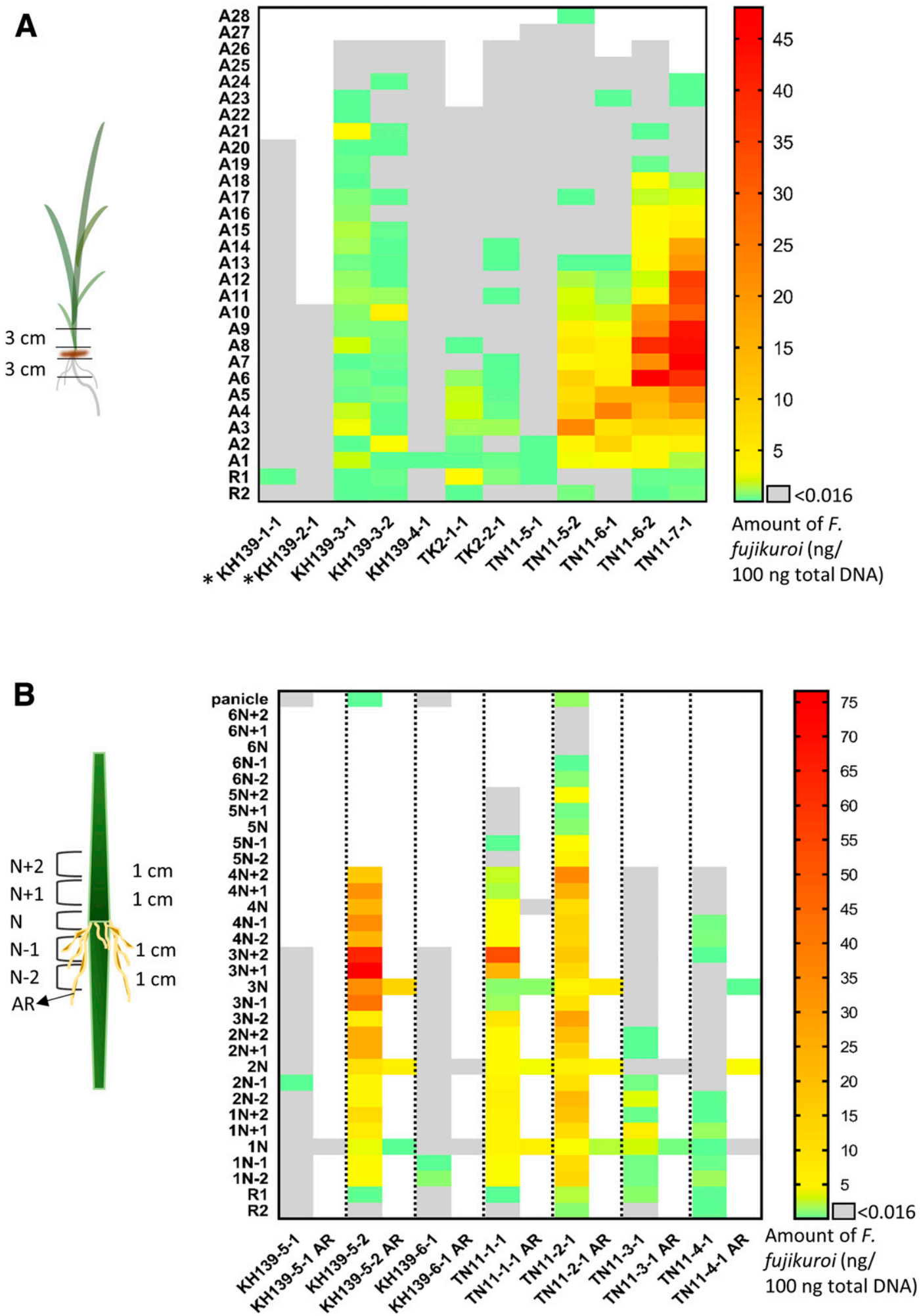

Fig. 7. qPCR analysis of the distribution of Fusarium fujikuroi in adult field plants. A, The amounts of $F$. fujikuroi in consecutive 3-cm segments of Kaohsiung 139 (KH139), Taikeng 2 (TK2), and Tainan 11 (TN11) plants. A\#, the segment number of the aerial parts of the plant; and R\#, the segment number of the root part. B, The amounts of $F$. fujikuroi in the nodes, internodes, and adventitious roots. \#N: the node number, counting from the base of the plant; N-1 or N-2: 1 or $2 \mathrm{~cm}$ below the node; $\mathrm{N}+1$ or N+2: 1 or $2 \mathrm{~cm}$ above the node; AR: adventitious roots emerged from the node. Plant ID: cultivar-hill-plant (details listed in Table 1). All plants showed typical symptoms of bakanae infection: elongation, slenderness, and yellowing. Adventitious roots were observed in all plants except KH139-1-1 and KH139-2-1 (labeled with *). 
plasmodesmata for cell-to-cell movement. It was recently discovered that a mitogen-activated protein kinase in $M$. oryzae, Pmk1, controls hyphal constriction and the expression of effectors implicated in suppression of host immunity and plasmodesmatal conductance (Sakulkoo et al. 2018). Based on our observations, the constricted hypha of $F$. fujikuroi measured $\sim 800 \mathrm{~nm}$ in diameter, which is also larger than the diameter of plasmodesmata. The mechanism of cell-to-cell invasion in $F$. fujikuroi needs further exploration.

It was observed that the degree of symptom severity did not necessarily correlate with the quantity of $F$. fujikuroi, both in the stem and roots and at the seedling and adult plant stages. While ZK and TNG67 showed distinct susceptible and resistant symptoms, microscopic observation and qPCR results suggested similar infection processes and $F$. fujikuroi biomasses within 21 dpi in these two cultivars. Among individual diseased seedlings of ZK or TNG67 showing similar elongation symptoms, the amounts of F. fujikuroi greatly varied (Supplementary Fig. S3). In diseased adult plants displaying similar symptoms, the longitudinal extension of $F$. fujikuroi could vary from approximately 6 to $84 \mathrm{~cm}$ above the stem base for TN11, 24 to $42 \mathrm{~cm}$ for TK2, and 3 to $72 \mathrm{~cm}$ for KH139 (Fig. 7A) (comparisons are based on plants collected from the same field at the same time). Previous studies also reported that susceptible-looking cultivars did not always contain more F. fujikuroi (Carneiro et al. 2017; Chen et al. 2019), and previously the expansion of $F$. fujikuroi in the stems of 11 diseased plants approaching the heading stage (collected from the same field) ranged from $10 \mathrm{~cm}$ to $105 \mathrm{~cm}$ above the base (Nisikado and Kimura 1939). Moreover, in a panel of 231 diverse rice lines, Chen et al. (2019) observed a weak correlation $(r=0.498)$ between disease severity index and colonization rate, and identified distinct QTLs for the two traits by genome-wide association analysis.

The formation of adventitious roots at the nodes is a distinct bakanae symptom observed in F. fujikuroi-infected adult plants. In deepwater rice, adventitious roots growing on the submerged nodes can support the main root system, which loses its function owing to the limited oxygen under flooded conditions (Steffens et al. 2006). Because the colonization of $F$. fujikuroi can cause dysfunction of vascular bundles in the roots and stem, whether the induction of adventitious roots plays a role in facilitating gas exchange and stress tolerance is worth further investigation. In this study, qPCR assays revealed that the appearance of adventitious roots does not reflect the quantity or the colonization site of $F$. fujikuroi in a rice plant. Even a small amount of $F$. fujikuroi colonization in the lower part of the plant could trigger the development of adventitious roots from the upper nodes with no infection. The emergence and growth of adventitious roots could be regulated by the interactions between GA, ethylene, and abscisic acid (Steffens et al. 2006).

Secondary metabolites produced by $F$. fujikuroi, such as GA, fusaric acid, and fumonisins, are key factors responsible for the abnormal elongation or stunting of infected host plants (Kurosawa 1926; Niehaus et al. 2016). We observed more elongation growth of ZK compared with TNG67 seedlings under treatment with $\mathrm{GA}_{3}$ at $0.5 \mathrm{mg} / \mathrm{liter}$, which indicated that the resistant and susceptible bakanae phenotypes of ZK and TNG67 are associated with their high and low sensitivities to $\mathrm{GA}_{3}$, respectively. A highly significant correlation between the response to $\mathrm{GA}_{3}(50 \mathrm{mg} / \mathrm{liter})$ and elongation symptoms caused by the bakanae pathogen was also revealed in 14 out of 24 rice genotypes carrying different dwarf and semidwarf genes (Ma et al. 2008); notably, the rice genotypes sensitive to $\mathrm{GA}_{3}$ were not always susceptible to bakanae disease (exceptions included the rice lines carrying $d 29, s d q(\mathrm{t})$ and two wild-type tall-plant genotypes, Nan-jing No.6 and Bei-ken-zi). For resistance breeding and disease control, considering the complex mechanisms underlying the development of bakanae symptoms, evaluation of not only morphological changes but also the sensitivity to GA and the level of F. fujikuroi colonization will help to more accurately assess the resistance and susceptibility of rice cultivars.

\section{ACKNOWLEDGMENTS}

We thank Ying-Lien Chen for providing the protoplasts of $F$. fujikuroi and the pPK2HPHGFP plasmid; Jenn-Wen Huang, Ruey-Fen Liou, Chi-Yu Chen, and Tsung-Chun Lin for suggestions on the experiments; and YuehLung $\mathrm{Wu}$ for sharing the qPCR machine.

\section{LITERATURE CITED}

Ali, M. L., McClung, A. M., Jia, M. H., Kimball, J. A., McCouch, S. R., and Georgia, C. E. 2011. A rice diversity panel evaluated for genetic and agromorphological diversity between subpopulations and its geographic distribution. Crop Sci. 51:2021-2035.

Amatulli, M. T., Spadaro, D., Gullino, M. L., and Garibaldi, A. 2012. Conventional and real-time PCR for the identification of Fusarium fujikuroi and Fusarium proliferatum from diseased rice tissues and seeds. Eur. J. Plant Pathol. 134:401-408.

Boenisch, M. J., and Schäfer, W. 2011. Fusarium graminearum forms mycotoxin producing infection structures on wheat. BMC Plant Biol. 11:110.

Carneiro, G. A., Matić, S., Ortu, G., Garibaldi, A., Spadaro, D., and Gullino, M. L. 2017. Development and validation of a TaqMan real-time PCR assay for the specific detection and quantification of Fusarium fujikuroi in rice plants and seeds. Phytopathology 107:885-892.

Chen, S. Y., Huang, K. J., Kuo, Y. F., Lai, M. H., Chen, Y. C., and Chung, C. L. 2015. Three modified methods for evaluation of bakanae disease resistance in rice seedlings. Plant Pathol. Bull. 24:201-210.

Chen, S. Y., Lai, M. H., Tung, C. W., Wu, D. H., Chang, F. Y., Lin, T. C., and Chung, C. L. 2019. Genome-wide association mapping of gene loci affecting disease resistance in the rice-Fusarium fujikuroi pathosystem. Rice (N. Y.) 12:85.

Chen, Y. C., Lai, M. H., Wu, C. Y., Lin, T. C., Cheng, A. H., Yang, C. C., Wu, H. Y., Chu, S. C., Kuo, C. C., Wu, Y. F., Lin, G. C., Tseng, M. N., Tsai, Y. C., Lin, C. C., Chen, C. Y., Huang, J. W., Lin, H. A., and Chung, C. L. 2016. The genetic structure, virulence, and fungicide sensitivity of Fusarium fujikuroi in Taiwan. Phytopathology 106:624-635.

Cook, M. E., Graham, L. E., Botha, C. E. J., and Lavin, C. A. 1997. Comparative ultrastructure of plasmodesmata of Chara and selected bryophytes: toward an elucidation of the evolutionary origin of plant plasmodesmata. Am. J. Bot. 84:1169-1178.

Desjardins, A. E., Manandhar, H. K., Plattner, R. D., Manandhar, G. G., Poling, S. M., and Maragos, C. M. 2000. Fusarium species from Nepalese rice and production of mycotoxins and gibberellic acid by selected species. Appl. Environ. Microbiol. 66:1020-1025.

Dong, H., Fan, H., Lei, Z., Wu, C., Zhou, D., and Li, H. 2019. Histological and gene expression analyses in banana reveals the pathogenic differences between races 1 and 4 of banana Fusarium wilt pathogen. Phytopathology 109:1029-1042.

Doyle, J. J., and Doyle, J. L. 1987. A rapid DNA isolation procedure for small quantities of fresh leaf tissue. Phytochem. Bull. 19:11-15.

Eizenga, G. C., Ali, M., Bryant, R. J., Yeater, K. M., McClung, A. M., and McCouch, S. R. 2014. Registration of the rice diversity panel 1 for genomewide association studies. J. Plant Regist. 8:109-116.

Fang, X., Kuo, J., You, M. P., Finnegan, P. M., and Barbetti, M. J. 2012. Comparative root colonisation of strawberry cultivars Camarosa and Festival by Fusarium oxysporum f. sp. fragariae. Plant Soil 358:75-89.

Gupta, A. K., Singh, Y., Jain, A. K., and Singh, D. 2014. Prevalence and incidence of bakanae disease of rice in northern India. J. AgriSearch 1: 233-237.

Gupta, A. K., Solanki, I. S., Bashyal, B. M., Singh, Y., and Srivastava, K. 2015. Bakanae of rice-an emerging disease in Asia. J. Anim. Plant Sci. 25: 1499-1514.

Haq, M., Mia, M. A. T., Rabbi, M. F., and Ali, M. A. 2011. Incidence and severity of rice diseases and insect pests in relation to climate change. Pages 445-457 in: Climate Change and Food Security in South Asia. R. Lal, M. V. K. Sivakumar, S. M. A. Faiz, A. H. M. M. Rahman, and K. R. Islam, eds. Springer, Dordrecht, Netherlands.

Hou, Z., Xue, C., Peng, Y., Katan, T., Kistler, H. C., and Xu, J. R. 2002. A mitogen-activated protein kinase gene $(M G V 1)$ in Fusarium graminearum is required for female fertility, heterokaryon formation, and plant infection. Mol. Plant-Microbe Interact. 15:1119-1127.

Huang, T. C., and Chu, S. C. 2009. The occurrence and control of rice bakanae disease in Taiwan. Pages 29-43 in: Proceeding of Symposium on Achievement and Perspectives of Rice Protection in Taiwan. Chiayi 
Agricultural Experiment Station, Taiwan Agricultural Research Institute, Chiayi, Taiwan.

Hur, Y. J., Lee, S., Kim, T., Kwon, T., Lee, J. H., Shin, D. J., Park, S. K., Hwang, U. H., Cho, J., Yoon, Y. N., Yeo, U. S., Song, Y. C., Kwak, D. Y., Nam, M. H., and Park, D. S. 2015. Mapping of $q B K 1$, a major QTL for bakanae disease resistance in rice. Mol. Breed. 35:78.

Ito, S., and Kimura, J. 1931. Studies on Bakanae disease of the rice plant. Rep. Hokkaido Agric. Exp. Stn. 27:1-95.

Jeon, Y. A., Yu, S. H., Lee, Y. Y., Park, H. J., Lee, S., Sung, J. S., Kim, Y. G., and Lee, H. S. 2013. Incidence, molecular characteristics and pathogenicity of Gibberella fujikuroi species complex associated with rice seeds from Asian countries. Mycobiology 41:225-233.

Jeong, H., Lee, S., Choi, G. J., Lee, T., and Yun, S. H. 2013. Draft genome sequence of Fusarium fujikuroi B14, the causal agent of the bakanae disease of rice. Genome Announc. 1:e00035-e13.

Kanjanasoon, P. 1965. Studies on bakanae disease of rice in Thailand. Thesis. Tokyo University.

Kankanala, P., Czymmek, K., and Valent, B. 2007. Roles for rice membrane dynamics and plasmodesmata during biotrophic invasion by the blast fungus. Plant Cell 19:706-724.

Karov, I. K., Mitrev, S. K., and Kostadinovska, E. D. 2009. Gibberella fujikuroi (Sawada) Wollenweber, the new parasitical fungus on rice in the Republic of Macedonia. Proc. Nat. Sci. Matica Srpska Novi Sad. 116: 175-182.

Kato, A., Miyake, T., Nishigata, K., Tateishi, H., Teraoka, T., and Arie, T. 2012. Use of fluorescent proteins to visualize interactions between the Bakanae disease pathogen Gibberella fujikuroi and the biocontrol agent Talaromyces sp. KNB-422. J. Gen. Plant Pathol. 78:54-61.

Khan, J. A., Jamil, F. F., and Gill, M. A. 2000. Screening of rice varieties/lines against bakanae and bacterial leaf blight (BLB). Pak. J. Phytopathol. 12: 6-11.

Kim, B. R., Han, K. S., Hahm, S. S., Kwon, M. K., and Nam, Y. G. 2015. Occurrence of the rice bakanae disease in Chungnam province. Res. Plant Dis. 21:154.

Kuo, C. C., Liao, C. T., Huang, D. C., Chen, Y. C., and Chung, C. L. 2014. Investigation of rice bakanae disease in central Taiwan: Occurrence, pathogen identification, and fungicide resistance assay. Res. Bull. Taichung Dist. Agric. Res. Ext. Stn. 125:11-28.

Kurosawa, E. 1926. Experimental studies on the nature of the substance secreted by the bakanae fungus. Nat. Hist. Soc. Formosa 16:213-227.

Lagopodi, A. L., Ram, A. F., Lamers, G. E., Punt, P. J., Van den Hondel, C. A., Lugtenberg, B. J., and Bloemberg, G. V. 2002. Novel aspects of tomato root colonization and infection by Fusarium oxysporum f. sp. radicis-lycopersici revealed by confocal laser scanning microscopic analysis using the green fluorescent protein as a marker. Mol. Plant-Microbe Interact. 15:172-179.

Leslie, J. F., and Summerell, B. A. 2006. The Fusarium Laboratory Manual. Blackwell Professional Publishing, Ames, IA.

Lin, C. Y. 2015. Characterization of Fusarium fujikuroi, with reference to the survival and the course of disease occurrence. MSc. Thesis. National Chung Hsing University.

Ma, L., Ji, Z., Bao, J., Zhu, X., Li, X., Zhuang, J., Yang, C., and Xia, Y. 2008. Responses of rice genotypes carrying different dwarf genes to Fusarium moniliforme and gibberellic acid. Plant Prod. Sci. 11:134-138.

Matić, S., Bagnaresi, P., Biselli, C., Orru', L., Carneiro, G. A., Siciliano, I., Valé, G., Gullino, M. L., and Spadaro, D. 2016. Comparative transcriptome profiling of resistant and susceptible rice genotypes in response to the seedborne pathogen Fusarium fujikuroi. BMC Genomics 17:608.

Matić, S., Gullino, M. L., and Spadaro, D. 2017. The puzzle of bakanae disease through interactions between Fusarium fujikuroi and rice. Front. Biosci. 9:333-344.

Michielse, C. B., van Wijk, R., Reijnen, L., Cornelissen, B. J., and Rep, M. 2009. Insight into the molecular requirements for pathogenicity of Fusarium oxysporum f. sp. lycopersici through large-scale insertional mutagenesis. Genome Biol. 10:R4.

Naito, H., Saito, K., Furuya, H., and Fuji, S. 2008. Morphology and fungal growth in elongated rice seedlings infected with Gibberella fujikuroi, and control of the disease in a flooded nursery. Jpn. J. Phytopathol. 74: 321-327.

Nguyen, T. T. X., Dehne, H. W., and Steiner, U. 2016. Histopathological assessment of the infection of maize leaves by Fusarium graminearum, $F$. proliferatum, and F. verticillioides. Fungal Biol. 120:1094-1104.

Niehaus, E. M., Münsterkötter, M., Proctor, R. H., Brown, D. W., Sharon, A., Idan, Y., Young, L. O., Sieber, C. M., Novák, O., Pěnčík, A., Tarkowská, D., Hromadova, K., Freeman, S., Maymon, M., Elazar, M., Youssef, S. A., El-Shabrawy, E. S. M., Shalaby, A. B. A., Houterman, P., Brock, N. L., Burkhardt, L., Tsavkelova, E. A., Dickschat, J. S., Galuszka, P., Güldener, U., and Tudzynski, B. 2016. Comparative "omics" of the Fusarium fujikuroi species complex highlights differences in genetic potential and metabolite synthesis. Genome Biol. Evol. 8:3574-3599.
Nirenberg, H. 1976. Untersuchungen über die morphologische und biologische differenzierung in Fusarium Sektion Liseola. Mitt. Biol. Bundesansi. LandForstwirtsch. Berlin-Dahlem 169:1-117.

Nisikado, Y., and Kimura, K. 1939. Microscopic examination of the rice stem infected by Fusarium fujikuroi (first report). Berichte des Ohara Instituts für landwirtschaftliche Forschungen. 31:341-347. (In Japanese)

Nisikado, Y., and Kimura, K. 1941. A contribution to the pathological anatomy of rice plants affected by Gibberella fujikuroi (Saw.). Berichte des Ohara Instituts für landwirtschaftliche Forschungen 8:421-426.

O’Donnell, K., Cigelnik, E., and Nirenberg, H. I. 1998. Molecular systematics and phylogeography of the Gibberella fujikuroi species complex. Mycologia 90:465-493.

Ou, S. H. 1985. Bakanae disease and foot rot. Pages 262-272 in: Rice Diseases. Commonwealth Mycological Institute, Kew, Surrey, England, U.K.

Ou, S. H. 1987. Rice Diseases. Commonwealth Mycological Institute, Kew, U.K.

Roth, R., Chiapello, M., Montero, H., Gehrig, P., Grossmann, J., O'Holleran, K., Hartken, D., Walters, F., Yang, S. Y., Hillmer, S., Schumacher, K., Bowden, S., Craze, M., Wallington, E. J., Miyao, A., Sawers, R., Martinoia, E., and Paszkowski, U. 2018. A rice serine/threonine receptor-like kinase regulates arbuscular mycorrhizal symbiosis at the peri-arbuscular membrane. Nat. Commun. 9:4677.

Sakulkoo, W., Osés-Ruiz, M., Garcia, E. O., Soanes, D. M., Littlejohn, G. R., Hacker, C., Correia, A., Valent, B., and Talbot, N. J. 2018. A single fungal MAP kinase controls plant cell-to-cell invasion by the rice blast fungus. Science 359:1399-1403.

Setter, T. L., Kupkanchanakul, T., Kupkanchanakul, K., Bhekasut, P., Wiengweera, A., and Greenway, H. 1987. Concentrations of $\mathrm{CO}_{2}$ and $\mathrm{O}_{2}$ in floodwater and in internodal lacunae of floating rice growing at 1-2 meter water depths. Plant Cell Environ. 10:767-776.

Singh, R., and Sunder, S. 1997. Foot rot and bakanae of rice: Retrospect and prospects. Int. J. Trop. Plant Dis. 15:153-176.

Steffens, B., Wang, J., and Sauter, M. 2006. Interactions between ethylene, gibberellin and abscisic acid regulate emergence and growth rate of adventitious roots in deepwater rice. Planta 223:604-612.

Sun, S. K. 1975. The diseases cycle of rice bakanae disease in Taiwan. Proc. Natl. Sci. Counc. Repub. China 8:245-256.

Sun, S. K., and Snyder, W. C. 1981. The bakanae disease of the rice plant. Pages 104-113 in: Fusarium: Diseases, Biology and Taxonomy. P. E. Nelson, T. A. Toussoun, and R. J. Cook, eds. The Pennsylvania State University Press, University Park, PA.

Sunani, S. K., Bashyal, B. M., Kharayat, B. S., Prakash, G., Krishnan, S. G., and Aggarwal, R. 2019. Identification of rice seed infection routes of Fusarium fujikuroi inciting bakanae disease of rice. J. Plant Pathol. 102: 113-121.

Valente, M. T., Desiderio, F., Infantino, A., Valè, G., Abbruscato, P., and Aragona, M. 2017. Genetic variability of Fusarium fujikuroi populations associated with bakanae of rice in Italy. Plant Pathol. 66:469-479.

Volante, A., Tondelli, A., Aragona, M., Valente, M. T., Biselli, C., Desiderio, F., Bagnaresi, P., Matic, S., Gullino, M. L., Infantino, A., Spadaro, D., and Valè, G. 2017. Identification of bakanae disease resistance loci in japonica rice through genome wide association study. Rice (N.Y.) 10:29.

Watanabe, Y. 1974. The possibility of soil transmission in bakanae disease and the contamination of seed with causal fungus during the hastening process of seed germination. Bull-Tokai-KinkiNat. Agric. Exp. Stn. 27:35-41.

Webster, R. K., and Gunnell, P. S. 1992. Compendium of Rice Disease, 1st ed. American Phytopathological Society, St. Paul, MN.

Wiemann, P., Sieber, C. M. K., von Bargen, K. W., Studt, L., Niehaus, E. M., Espino, J. J., Huß, K., Michielse, C. B., Albermann, S., Wagner, D., Bergner, S. V., Connolly, L. R., Fischer, A., Reuter, G., Kleigrewe, K., Bald, T., Wingfield, B. D., Ophir, R., Freeman, S., Hippler, M., Smith, K. M., Brown, D. W., Proctor, R. H., Münsterkötter, M., Freitag, M., Humpf, H. U., Güldener, U., and Tudzynski, B. 2013. Deciphering the cryptic genome: Genome-wide analyses of the rice pathogen Fusarium fujikuroi reveal complex regulation of secondary metabolism and novel metabolites. PLoS Pathog 9:e1003475.

Yabuta, T., and Sumiki, Y. 1938. On the crystal of gibberellin, a substance to promote plant growth. J. Agric. Chem. Soc. Jpn. 14:1526.

Yu, S. M., Lo, S. F., and Ho, T. H. D. 2015. Source-sink communication: Regulated by hormone, nutrient, and stress cross-signaling. Trends Plant Sci. 20:844-857.

Zainudin, N. A. I. M., Razak, A. A., and Salleh, B. 2008. Bakanae disease of rice in Malaysia and Indonesia: Etiology of the causal agent based on morphological, physiological and pathogenicity characteristics. J. Plant Prot. Res. 48:475-485.

Zheng, Z. W., Chang, S. J., and Chu, S. C. 2016. The occurrence of bakanae disease and fungicide resistance of Fusarium fujikuroi on rice paddy, seedlings and seeds from Miaoli. Res. Bull. Miaoli Dist. Agric. Res. Ext. Stn. 4:59-72. 